\title{
Redox signaling: hydrogen peroxide as intracellular messenger
}

\author{
Sue Goo Rhee \\ Laboratory of Cell Signaling, \\ National Heart, Lung, and Blood Institute, National Institutes of Health, Bethesda, \\ Maryland 20892, U.S.A. \\ E-mail, sgrhee@nih.gov; Tel., 301-496-9646; Fax, 301-480-0357 \\ Accepted 6 May 1999
}

Abbreviations: TNF, tumor necrosis factor; PDGF, platelet-derived growth factor; EGF, epidermal growth factor; ROS, reactive oxygen species; NO, nitric oxide; PTPIB, protein tyrosine phosphatase $1 \mathrm{~B}$

\begin{abstract}
Although superoxide anions $\left(\mathrm{O}_{2}^{--}\right)$and $\mathrm{H}_{2} \mathrm{O}_{2}$ are generally considered to be toxic by-products of respiration, recent evidence suggests that the production of these reactive oxygen species (ROS) might be an integral component of membrane receptor signaling. In mammalian cells, a variety of extracellular stimuli have recently been shown to induce a transient increase in the intracellular concentration of ROS, and specific inhibition of the ROS generation resulted in a complete blockage of stimulant-dependent signaling. In the next few years, therefore, a flurry of research activity is expected in relation to the elucidation of ROS production in response to receptor stimulation, identification of ROS target molecules, and investigation of ROS elimination. The goal of this report is to review our current knowledge of ROSregulated signal trans-duction and propose future directions.
\end{abstract}

Keywords: redox, hydrogen peroxide, ROS, signaling

\section{Introduction}

The process that transduces the extracellular messages carried by first messengers such as hormones, growth factors, cytokines, and neurotransmitters across plasma membranes into the intracellular components is called signal transduction or cell signaling. An important feature of the signal transduction is that the first messenger molecules need not enter the cell and their biological effects are mediated inside the cell by second messenger molecules such as cAMP, cGMP, inositol 1,4,5-trisphos- phate (Ins 1,4,5-P3), nitric oxide, and phosphatidylinositol 1,3,4,5-tetrakisphosphate (Ptdlns 1,3,4,5-P4). The second messenger generation process involves various cellular components like specific receptors, transducers, adaptor proteins, protein kinases, and protein phosphatases, and eventually lead to the induction of physiological responses such as gene expression, cell proliferation, secretion, cell motility, and neurotransmission.

Recently, reactive oxygen species (ROS) gained attention as important second messengers. For example, hydrogen peroxide $\left(\mathrm{H}_{2} \mathrm{O}_{2}\right)$ mimics the stimulatory effects of insulin on glucose transport and lipid synthesis in adipocytes (May and De Haen, 1979). The production of ROS has been detected in a variety of cells stimulated with cytokines such as transforming growth factor- $\beta 1$ (TGFß1) (Ohba et al., 1994; Thannickal and Fanburg, 1995), interleukin-1 (Meier et al.,1989), and tumor necrosis factor- $\alpha$ (TNF- $\alpha$ ) (Meier et al.,1989; Lo and Cruz, 1995), with peptide growth factors such as platelet-derived growth factor (PDGF) (Krieger-Brauer and Kather, 1995; Sundaresan et al., 1995), epidermal growth factor (EGF) (Bae et al., 1997), and basic fibroblast growth factor (bFGF) (Krieger-Brauer and Kather, 1995; Lo and Cruz, 1995), with agonists of receptors with seven transmembrane spans such as angiotensin II (Griendling et al., 1994), thrombin (Chen et al., 1995) and lysophosphatidic acid (Chen et al., 1995) or with phorbol ester (Robertson et al., 1990) and phosphatidic acid (Lee et al., 1998). The term ROS encompasses many species including singlet oxygen, the superoxide anion radical $\left(\mathrm{O}_{2}{ }^{-}\right), \mathrm{H}_{2} \mathrm{O}_{2}$, lipid peroxides, nitric oxide (NO), peroxynitrite (ONOO-), the thiyl peroxyl radical (RSOO), the ferryl radical $\left(\mathrm{FeO}^{2+}\right)$ and the hydroxyl radical $\left(\mathrm{OH}^{-}\right)$(Moncada et al., 1991; Stadtman and Oliver, 1991; Huie and Padmaja, 1993; Yim et al., 1994).

Although the chemical nature of ROS generated in response to the activation of various receptors has not been well characterized, $\mathrm{H}_{2} \mathrm{O}_{2}$ was shown to be a major component of ROS in cells activated by TGF- $\beta 1$, PDGF, EGF, or angiotensin II (Ohba et al., 1994; Sundaresan et al., 1995; Bae et al., 1997). The generation of ROS in response to various external stimuli has been related to the activation of transcription factors such as NF- $\mathrm{KB}$ (Schreck et al., 1991) and AP-1 (Pahl and Baeuerle, 1994; Lo and Cruz, 1995), mitogen-activated protein (MAP) kinases (Chen et al., 1995; Sundaresan et al., 1995), phospholipase $A_{2}$ (Zor et al., 1993), protein kinase C (Konishi et al., 1997), and phospholipase D (Natarajan et al., 1993; Min et al., 1998), to increasing cytosolic calcium (Suzuki et al., 1997), to the triggering of apoptosis (Jacobson, 1996), to the inhibition of protein tyrosine phosphatases (PTPase) (Hecht and Zick, 1992; Sullivan 
et al., 1994; Lee et al., 1998), and to the alteration of ion transport mechanisms (Kourie, 1998). $\mathrm{H}_{2} \mathrm{O}_{2}$ is a small, diffusible, and ubiquitous molecule that can be synthesized, as well as destroyed, rapidly in response to external stimuli. As such it fulfills the important prerequisites for an intracellular messengers.

Even in the absence of extracellular stimulation, super-oxide anions $\left(\mathrm{O}_{2}{ }^{-}\right)$is constantly produced by metabolic reactions in all aerobic organisms. The $\mathrm{O}_{2}{ }^{--}$is then spontaneously or enzymatically dismutated to $\mathrm{H}_{2} \mathrm{O}_{2}$. In addition, cells are exposed to irradiations ( $x-$ rays, gamma-rays, ultraviolet light), inflammatory systems, metal-catalyzed oxidation systems, environmental pollutants inevitably produce ROS (Stadtman and Berlett, 1998). Whereas any one of the ROS is able to damage cellular components, hydroxyl radicals $(\mathrm{OH})$, causes damage indiscriminately. And there is reason to believe that the most important mechanism of $\mathrm{OH}$ generation inside cells is from $\mathrm{H}_{2} \mathrm{O}_{2}$ via Fenton reaction $\left[\mathrm{H}_{2} \mathrm{O}_{2}+\mathrm{Fe}(\mathrm{II})\right.$ or $\mathrm{Cu}(\mathrm{I})$ and $\mathrm{OH}^{-}+$ $\mathrm{OH}+\mathrm{Fe}(\mathrm{III})$ or $\mathrm{Cu}(\mathrm{II})]$ (Stadtman and Berlett, 1998). Cellular electron donors such as NADH, NADPH, ascorbate, various thiol compounds are able to regenerate $\mathrm{Fe}(\mathrm{II})$ or $\mathrm{Cu}(\mathrm{I})$. For these reasons, $\mathrm{O}_{2}{ }^{-}$and $\mathrm{H}_{2} \mathrm{O}_{2}$ have been thought of as the unwanted and toxic byproducts of living in an aerobic environment. Though the cell had clearly evolved mutiple defences for their elimination, their relentless production coupled with their damaging nature has led to the widely held belief that these molecules serve only a harmful function.

However, the notion that molecules like $\mathrm{O}_{2}{ }^{-}$and $\mathrm{H}_{2} \mathrm{O}_{2}$ could function in signal transduction in mammalian cells is not without precedent. Indeed, a wealth of information suggests that these molecules serve as signaling molecules in both bacteria and plants. In bacteria, redox regulation of transcription occurs, with a different set of genes stimulated by $\mathrm{O}_{2} \cdot-$ and $\mathrm{H}_{2} \mathrm{O}_{2}$ (Hidalgo et al., 1997; Rosner and Storz, 1997; Zheng et al., 1998). Similarly in the plant response to pathogen, there appears to be a clear role for $\mathrm{H}_{2} \mathrm{O}_{2}$ as a signaling molecule (Levine et al., 1994; Shirasu et al., 1996). Salicylic acid binds to and inactivates tobacco catalase, leading to a rise in $\mathrm{H}_{2} \mathrm{O}_{2}$ concentration and the activation of gene transcription (Chen et al., 1993). In mammalian cells, the physiological role for $\mathrm{O}_{2}$-- $^{-}$and $\mathrm{H}_{2} \mathrm{O}_{2}$ is less characterized than that of another ROS, namely nitric oxide (NO).

Analysis of the role of NO suggests it fuctions in two discrete fashions. Production of NO by macrophages and other immune cells results in the high level production of $\mathrm{NO}$, consistent with its role in host defense. In contrast, the nitric oxide synthetase in nonphagocytic cells produce 2-3 orders of magnitude less NO when activated. Product at this level, NO is widely believed to function in cell signaling (Finkel, 1998). This dichotomy between defence function and signal transduction is likely to be preserved for $\mathrm{O}_{2} \cdot-$ and $\mathrm{H}_{2} \mathrm{O}_{2} \cdot \mathrm{O}_{2} \cdot{ }^{--}$and $\mathrm{H}_{2} \mathrm{O}_{2}$ are also produced in large amounts by phagocytic cells. In contrast, other cell types appear to produce significantly lower amounts of these molecules. Emerging evidence suggests that this minimal oxidative burst appears to serve an important role in signal transduction (Finkel, 1998).

Since the introduction of the second messenger concept as the result of the pioneering work on CAMP by Earl W. Jr. Sutherland (Recipient of the 1970 Nobel Prize in Physiology and Medicine), all branch of life sciences including medicine have gained tremendous insight by studying how receptor occupation elicits the production of a second messenger, what kinds of molecules are targeted by the produced messenger, and how the messenger molecules are eliminated after the completion of their mission. For example, related to cAMP and CGMP, studies on the coupling mechanism of receptors to adenylate and guanylate cyclases, protein phosphorylation events initiated by the activation of cyclic nucleotide-dependent kinases, removal of cAMP and CGMP by phosphodiesterases have been the center pieces of Biochemistry, Pharmacology, Endocrinology, and Immunology for many years. These studies led to the discovery of G-proteins by Alfred G. Gilman and Martin Rodbell (Recipients of the 1994 Nobel laureates in Physiology and Medicine) and to the discovery by Edmond H. Fischer and Edwin G. Krebs (Recipients of the 1992 Nobel laureates in Physiology and Medicine) of fundamental principles concerning reversible protein phosphorylation as a biological regulatory mechanism. These studies provided not only new principles of science but many useful sites where useful therapeutic agents can be designed for intervention. Viagra, developed as an inhibitor of cGMP phosphodiesterase is an example. It is also significant to note that the 1998 Nobel Prize in Physiology and Medicine was given, in recognition of the discoveries concernig nitric oxide as a signaling molecule, to Robert F. Furchgott, Louis J. Ignarro, and Ferid Murad.

At the present time, very little is known about 1) the mechanism by which $\mathrm{H}_{2} \mathrm{O}_{2}$ is generated in response to receptor stimulation in nonphagocytic cells, 2) the molecules on which $\mathrm{H}_{2} \mathrm{O}_{2}$ acts to propagate the signal, and 3 ) the controlled pathway by which $\mathrm{H}_{2} \mathrm{O}_{2}$ is timely removed. Studies on these three subjects, production, target, and elimination, are expected to be important area in biochemistry.

\section{Production of $\mathrm{H}_{2} \mathrm{O}_{2}$ in response to receptor stimulation in nonphagocytic cells}

The mechanism of the receptor-mediated generation of ROS has been studied extensively in phagocytic cells, in which $\mathrm{O}_{2}{ }^{-}$(and thus $\mathrm{H}_{2} \mathrm{O}_{2}$ ) is produced via the reduction of $\mathrm{O}_{2}$ by a complicated enzyme system named NADPH 
oxidase (Thelen et al., 1993). The NADPH oxidase consists of at least four polypetide components, two cytosolic components (p47- and p67-phox) and two transmembrane flavocytochrome b components (gp91- and p22-phox). The activation of NADPH oxidase involves a specific protein-protein interaction (via SH3-prolin-rich domains) and phosphorylation by various protein kinases At least one additional protein, the small GTP-binding protein Rac (either Rac 1 or Rac 2), is needed for NADPH oxidase activation. In contrast, the mechanism of $\mathrm{H}_{2} \mathrm{O}_{2}$ generation in nonphagocytic cells remains unclear.

Neither immunoblot nor Northernblot analysis using molecular probes derived from the NADPH oxidase components of phagocytes detected similar components in nonphagocytic cells. However, the production of $\mathrm{H}_{2} \mathrm{O}_{2}$ in fibroblasts stimulated by PDGF, EGF, II-1, or TNF- $\alpha$ appears to be mediated by a Rac-sensitive system (Sundaresan et al., 1996). Furthermore, treatment with diphenyleneiodonium, a pharmacological inhibitor of the flavoprotein component of the neutrophil NADPH oxidase, appears to significantly affect ROS production in nonphagocytic cells stimulated by first messengers or expression of activated rac (Griendling et al., 1994; Ohba et al., 1994). In addition, inhibiting the expression of one of the ubiquitously expressed components, p22phox, was recently shown to inhibit the ability of angiotensin II to stimulate $\mathrm{H}_{2} \mathrm{O}_{2}$ production in vascular smooth muscle cells (Ushio-Fukai et al., 1996). Together with the fact that overproduction of Rac in fibroblasts enhances $\mathrm{H}_{2} \mathrm{O}_{2}$ production, these results suggest that the system responsible for $\mathrm{H}_{2} \mathrm{O}_{2}\left(\mathrm{O}_{2} \cdot\right)$ production in nonphagocytes is structurally and genetically distinct but functionally similar to the NADPH oxidase system of phagocytic cells.

Evidence suggests that the receptor-triggered generation of $\mathrm{H}_{2} \mathrm{O}_{2}$ in nonphagocytic cells occurs independently of the mitochondrial respiratory chain and xanthine oxidase system (Meier et al.,1989). However, a variety of cellular enzymes including cyclooxygenases and lypoxygenases are also potential agonist-activated $\mathrm{H}_{2} \mathrm{O}_{2}$ generating system.

Because uncontrolled generation of $\mathrm{H}_{2} \mathrm{O}_{2}$ is toxic to cells, basal actvity of the putative nonphagocytic NADPH oxidase is expected to be very low. As with other second sessenger-generating systems (e.g. adenylate cyclase and phospholipase $\mathrm{C}$ ) widely used in receptor signaling, various protein and lipid kinases (phosphatases) and G proteins are likely to be involved in the modulation of the nonphagocytic NADPH oxidase. Additionally, these nonphagocytic components are expected to be subject to control by other second messenger-generating cascades. Considering that the nonphagocytic NADPH oxidase must maintain near zero basal activity and be activated in response to different (cytokine, growth factor, G protein-coupled) receptors, new modes of signal propagation are expected to be uncovered during the study.
In an effort to understand the $\mathrm{H}_{2} \mathrm{O}_{2}$ production mechanism, the dependence of $\mathrm{H}_{2} \mathrm{O}_{2}$ production on the intrinsic tyrosine kinase activity of the EGF receptor and the autophosphorylation sites located in its $\mathrm{COOH}$ terminal tail was investigated (Bae et al., 1997). EGF failed to induce $\mathrm{H}_{2} \mathrm{O}_{2}$ generation in cells expressing a kinase-inactive EGF receptor. However, normal $\mathrm{H}_{2} \mathrm{O}_{2}$ generation was observed in cells expressing a mutant receptor from which the $126 \mathrm{COOH}$-terminal amino acids had been deleted to remove four (out of the total of five) autophosphorylation sites. These relts suggest that EGF-induced $\mathrm{H}_{2} \mathrm{O}_{2}$ formation requires the kinase activity, but probably not the autophosphorylation sites, of the EGF receptor.

\section{Target molecules on which $\mathrm{H}_{2} \mathrm{O}_{2}$ acts to propagate the signal}

$\mathrm{H}_{2} \mathrm{O}_{2}$ is generated in all aerobic organisms as the result of normal cellular metabolism. Since $\mathrm{H}_{2} \mathrm{O}_{2}$ is readily converted to hydroxyl radicals via the Fenton reaction, it is considered a cytotoxic agent that causes damage to many cellular components. Oxidative damage has been implicated in numerous disorders and the general process of aging. Accordingly, the target for ROS action has been studied mainly in relation to these disorders, leading to the identification of irreversibly damaged cellular components. The second messenger role of $\mathrm{H}_{2} \mathrm{O}_{2}$ requires reversible modification by or binding of $\mathrm{H}_{2} \mathrm{O}_{2}$. However, to date no serious efforts to identify such targets can be found in literature.

Unlike cAMP and Ins $1,4,5-\mathrm{P}_{3}, \mathrm{H}_{2} \mathrm{O}_{2}$ is too simple structurally to be recognized specifically by proteins. Thus, it is unlikely that reversible binding of $\mathrm{H}_{2} \mathrm{O}_{2}$ to proteins is a means of propagating a specific signal. On the other hand, $\mathrm{H}_{2} \mathrm{O}_{2}$ is a mild oxidant that can oxidize specific protein sulfhydryl groups, producing proteins with cysteine sulfenic acid (CysS-OH) or disulfide residues, both of which can easily be reduced back to Cys-SH by various cellular reductants. Very few proteins are expected to have a Cys-SH that is susceptible to oxidation by $\mathrm{H}_{2} \mathrm{O}_{2}$ in cells because oxidation requires that the target $\mathrm{Cys}-\mathrm{SH}$ have a pKa below 7.0, whereas the $\mathrm{pKa}$ values of most protein $\mathrm{Cys}-\mathrm{SH}$ residues are higher than 8.0. Proteins like thioredoxin (Holmgren, 1989) protein disulfide isomerase (Freedman et al., 1994), protein tyrosine phosphatases (PTPases) (Lohs et al., 1997; Lee et al., 1998), cysteine proteases (Caspases) (Ischiropoulos, 1998), and peroxiredoxins (Choi et al., 1998), which are known to contain an essential Cys-SH with a low pKa at their active sites, are potential candidates for reversible oxidation by intracellularly generated $\mathrm{H}_{2} \mathrm{O}_{2}$. Protein methionine residues are also sensitive to oxidation by $\mathrm{H}_{2} \mathrm{O}_{2}$ and easily converted to methionine sulfoxide, and cells are known to contain protein methionine sulfoxide reductase that reduces the oxidized methionine using 
NADPH (Levine et al., 1996). However, unlike cysteine residues that have been defined for the structural and catalytic roles in many proteins, no known catalytic and regulatory functions have been associated with methionine.

Several serine/threonine kinases such as CAMP. dependent kinase (PKA), cGMP-dependent kinase (PKG), Akt kinase, $S 6$ kinase, and protein kinase $C$ (PKC) all contain a Cys-SH residue within their active site domain (Hanks and Quinn, 1991). Interestingly, these Cys-SH residues are not required for activity but they are fully conserved among these kinases. One can hypothesize that the oxidation of these conserved Cys residues, although their pKa values are not known, is related to the observation that the activity of these kinases are altered in cells treated with $\mathrm{H}_{2} \mathrm{O}_{2}$. Interaction with regulatory subunits (or molecules) may be modulated by the reversible oxidation of this $\mathrm{Cys}-\mathrm{SH}$.

The signal transduction roles of $\mathrm{H}_{2} \mathrm{O}_{2}$ generated in response to peptide growth factor were studied with PDGF and EGF (Sundaresan et al., 1995; Bae et al., 1997). Stimulation of rat vascular smooth muscle cells (VSMCs) by PDGF transiently increased the intracellular concentration of $\mathrm{H}_{2} \mathrm{O}_{2}$, and this increase could be blunted by increasing the intracellular concentration of catalase (Sundaresan et al., 1995). The responses of VSMCs to PDGF, which includes tyrosine phosphorylation, MAP kinase activation, DNA synthesis, and chemotaxis, was inhibited when the PDGF-stimulated rise in $\mathrm{H}_{2} \mathrm{O}_{2}$ concentration was blocked. In another experiment, the elimination of $\mathrm{H}_{2} \mathrm{O}_{2}$ by catalase in $\mathrm{A} 431$ human epidermoid carcinoma cells also resulted in inhibition of the EGFinduced tyrosine phosphorylation of various cellular proteins including, the EGF receptor and phospholipase C- $\gamma 1$ (Bae et al., 1997). These results suggested that $\mathrm{H}_{2} \mathrm{O}_{2}$ may act as a second messenger molecule.

Reversible inactivation of the PTPase family members by $\mathrm{H}_{2} \mathrm{O}_{2}$ may explain why the production of $\mathrm{H}_{2} \mathrm{O}_{2}$ is required in many cases for receptor-induced tyrosine phosphorylation. To investigate this possibility, the effect of $\mathrm{H}_{2} \mathrm{O}_{2}$ produced in response to EGF on the activity of protein tyrosine phosphatase $1 \mathrm{~B}$ (PTP1B) was investiga-ted in A431 (Lee et al., 1998). $\mathrm{H}_{2} \mathrm{O}_{2}$ inactivated recom-binant PTP1B in vitro by oxidizing its catalytic site cysteine, most likely to sulfenic acid. The oxidized enzyme was reactivated more effectively by thioredoxin than by gluta-redoxin or glutathione at their physiological concentrations. Oxidation by $\mathrm{H}_{2} \mathrm{O}_{2}$ prevented modification of the catalytic cysteine of PTP1B by iodoacetic acid, suggesting that it should be possible to monitor the oxidation state of PTP1B in cells by measuring the incorporation of radio-activity into the enzyme after lysis of the cells in the presence of radiolabeled iodoacetic acid. The amount of such radioactivity associated with $\mathrm{PTP} 1 \mathrm{~B}$ immunoprecipitated from A431 cells that had been stimulated with EGF for 10 min was $27 \%$ less than that associated with
PTP1B from unstimulated cells. The amount of iodoacetic acid-derived radioactivity associated with PTP1B reached a minimum 10 min after stimulation of cells with EGF and returned to baseline values by $40 \mathrm{~min}$, suggesting that the oxidation of PTP1B is reversible in cells.

On the basis of the previous observation that growth factor-induced protein tyrosine phosphorylation requires $\mathrm{H}_{2} \mathrm{O}_{2}$ production and this current observation that growth factor-induced generation of $\mathrm{H}_{2} \mathrm{O}_{2}$ is sufficient to cause inactivation of PTP1B, it was proposed that the activation of a receptor PTK by interaction with a growth factor may not be sufficient to increase the steady state level of protein tyrosine phosphorylation in a cell; rather, concurrent inhibition of PTPs by $\mathrm{H}_{2} \mathrm{O}_{2}$ may also be required for this effect. The extent of tyrosine phosphorylation of receptor PTKs and their substrates would then return to basal values after degradation of $\mathrm{H}_{2} \mathrm{O}_{2}$ and the subsequent reactivation of PTPs by electron donors. In vitro data suggested that Trx might be a physiological electron donor for PTP1B. This was the first direct demonstration linking the oxidation of protein Cys residues to signaling, and confirmed the hypothesis that reversible oxidation by $\mathrm{H}_{2} \mathrm{O}_{2}$ is a means of signal propagation. This hypothesis is also consistent with the suggestion that the ligand-independent basal activity of receptor PTKs might be sufficient to increase the extent of protein tyrosine phos-phorylation in cells treated with thiol-alkylating agents, such as iodoacetic acid and iodoacetamide, or oxidants, such as ultraviolet light, that cause the inactivation of PTPs (Knebel et al., 1996). Likewise, reversible oxidation of the essential Cys residues of Caspase family members, which are implicated in apoptosis, may account for the observed role of $\mathrm{H}_{2} \mathrm{O}_{2}$ in apoptosis. Ras is also likely a target of $\mathrm{H}_{2} \mathrm{O}_{2}$ : Recently, Cys118 of Ras was shown to be modified by NO, triggering downstream signaling events (Lander et al., 1996).

Both prokaryotic and higher eukaryotic cells are able to alter their genetic program in response to changes in the intracellular levels of ROS. In bacteria and yeast, this response leads to the new synthesis of proteins that protects cells from the consequences of oxidative damage. The resposne to oxidative stress has been extensively studied in E. coli (Rosner and Storz, 1997). In E. coli two transcriptional factor systems, SoxR and OxyR, have been identified that activate expression of genes whose products are involved in either the protection from oxi-dative stress or the repair of ROS-mediated damage. Intriguingly, the two transcriptional factors respond to different ROS species. SoxR/R with ironsulfur center is activated by $\mathrm{O}_{2}$ - $^{-}$(Hidalgo et al., 1997), whereas OxyR is selectively induced by $\mathrm{H}_{2} \mathrm{O}_{2}$ (Zheng et al., 1998). In vitro and in vivo studies of oxidized OxyR revealed that the transcriptional factor is activated through the formation of a disulfide bond and is deactivated by reduction with glutaredoxin (Zheng et al., 
1998).

$\mathrm{NF}-\mathrm{KB}$ was the first eukaryotic transcription factor shown to respond directly to oxidative stress (Schreck et al., 1991; Baeuerle and Baltimore, 1996; Kretz-Remy et al., 1996). The transactivator plays a crucial role in the regulation of numerous genes involved in immune and inflammatory processes. Potent stimuli activating NF- kB in intact cells are the TNF- $\alpha$ and IL-1, phorbol ester, LPS, and UV radiation. Interestingly, many, if not all NF- $\kappa B$-inducing agents lead to an increase in the intracellular concentration of ROS. Furthermore, exposure of several types of cells to $\mathrm{H}_{2} \mathrm{O}_{2}$ rapidly induced NF- kB activation, sugggesting that $\mathrm{H}_{2} \mathrm{O}_{2}$ might be the mediator of prooxidant-induced NF - $\mathrm{kB}$ activation. As frequently speculated in literature, the essential Cys residues of transcriptional factors (c-fos, c-jun, NF- $\kappa B$, hypoxia-inducible transcription factor- 1 ) are likely targets of $\mathrm{H}_{2} \mathrm{O}_{2}$ modification and this modification together with phosphorylation events may be responsible for their complex signaling mechanisms. In addition to the predicted target proteins mentioned above, there are likely many more target proteins to be discovered.

\section{Elimination of $\mathrm{H}_{2} \mathrm{O}_{2}$}

Conventional antioxidant enzymes like superoxide dismutase, catalase, glutathion peroxidase and small antioxidant molecules like a-tocopherol, lipoic acid, ascorbic acid, and uric acid are believed to exist in order to remove ROS or repair damage caused by ROS. The roles of these antioxidant molecules in cell function have been studied extensively with the hope of gaining an upper hand against various human diseases and to fight the process of aging. However, given the recent indications on the messenger role of $\mathrm{H}_{2} \mathrm{O}_{2}$, many investigators in the area of antioxidant defense have turned their attention to cell signaling and have suggested certain roles for various antioxidants.

Our interest in $\mathrm{H}_{2} \mathrm{O}_{2}$ was triggered by our discovery of a thioredoxin-dependent peroxidase (TPx) from yeast that reduces $\mathrm{H}_{2} \mathrm{O}_{2}$ with thioredoxin (Trx) as an immediate electron donor (Chae et al., 1993; Chae et al., 1994; Chae et al., 1994; Kim et al., 1998). A database search revealed more than 40 proteins from a wide variety of species that show sequence similarity to yeast TPx (Chae et al., 1994). These homologous proteins were named the peroxiredoxin (Prx) family (Chae et al., 1994). They were not termed the TPx family because not all members use Trx as the hydrogen donor. Initially, we regarded the yeast enzyme to be another antioxidant enzyme that simply protected cellular components from oxidative damage and we called it thiol-specific antioxidant (TSA) (Chae et al., 1993; Chae et al., 1994). Subsequently we found that like many proteins involved in signal transduction, Prx exists as mutiple (at least six) isoforms in mammalian cells. Furthermore, several of the Prx isoforms were discovered in connection with cellular functions such as proliferation, differentiation, natural killer cell activity, osteoregulation, and keratinocyte function. These seemingly unrelated functions, which were reported without reference to any peroxidase activity, led us to hypothesize that Prx proteins participate in the signaling cascade of various receptors by regulating the intra-cellular concentration of $\mathrm{H}_{2} \mathrm{O}_{2}$. $A$ is exemplified by the examples of cAMP, cGMP, and Ins 1,4,5-P3, the controlled removal of second messenger molecules is an important feature of receptor signaling. To date, catalase and GPx have been viewed as the major enzymes responsible for removal of cytotoxic $\mathrm{H}_{2} \mathrm{O}_{2}$. However, catalase is largely or entirely localized in peroxisomes and GPx is present mainly in mitochondria and nuclei. Additionally, small molecular antioxidants like a-tocopherol, lipoic acid, ascorbic acid, and uric acid show low reducing activity toward $\mathrm{H}_{2} \mathrm{O}_{2}$. In contrast, five of the six Prx isoforms are abundant in the cytosol and are found in almost every tissue.

We investigated the cellular function of mammalian Prx members by transiently expressing them in various cultured cells. Overexpression of a wild-type Prx in $\mathrm{NIH}$ 3 T3 cells and A431 cells completely overcame the $\mathrm{H}_{2} \mathrm{O}_{2}$ increase in response to growth factor and inhibits the activation of c-jun N-terminal kinase (JNK) induced by $\mathrm{H}_{2} \mathrm{O}_{2}$ or growth factors, whereas expression of the inactive mutant lacking the active Cys had no effect (Jin et al., 1997; Kang et al., 1998; Kang et al., 1998). Furthermore, overexpression of a peroxiredoxin in HeLa cells inhibited both the NF- $\mathrm{KB}$ activation and apoptosis elicited by $\mathrm{H}_{2} \mathrm{O}_{2}$ or TNF- $\alpha$ (Jin et al., 1997; Zhang et al., 1997; Kang et al., 1998; Kang et al., 1998). These results suggest that Prx proteins act as a regulator of intracellular $\mathrm{H}_{2} \mathrm{O}_{2}$ concentration and signal transduction. These conclusions are consistent with the fact that Prx proteins were discovered in connection with a variety of seemingly unrelated cellular processes such as proliferation, natural killer cell activity, the response to oxidative stress, and osteoregulation. An immediate question to be addressed is how the peroxidase activity of Prx enzymes is modulated in response to receptor occupancy.

\section{Concluding remarks}

Over the next several years, $\mathrm{H}_{2} \mathrm{O}_{2}$ is expected to join the ranks of cAMP, $\mathrm{Ca}^{2+}$, Ins 1,4,5-P3, and $\mathrm{NO}$ in its role as a second messenger as a result of the contribution of many laboratories throughout the world. A plethora of new scientific principles have been established through studies on the mechanisms for the production and elimination of the messengers and during identification of downstream targets. History shows that advances in the basic understanding of cell signaling have invariably led to the means of developing new theraputic reagents. Studies on $\mathrm{H}_{2} \mathrm{O}_{2}$ will be no exception to this legacy of discovery and application. 


\section{References}

Bae, Y. S., Kang, S. W., Seo, M. S., Baines, I. C., Tekle, E., Chock, P. B., and Rhee, S. G. (1997) Epidermal growth factor (EGF)-induced generation of hydrogen peroxide. Role in EGF receptor-mediated tyrosine Phos-phorylation. J. Biol. Chem. 272: 217-221

Baeuerle, P. A. And Baltimore, D. (1996) NF-kappa B: ten years after. Cell 87, 13-20

Chae,H. Z., Chung, S. J. and Rhee,S. G. (1994) Thioredoxin-dependent peroxide reductase from yeast. J. Biol. Chem. 269: 27670-27678

Chae,H. Z., Kim, I.-H., Kim, K. and. Rhee, S. G (1993) Cloning, sequencing, and mutation of thiol-specific antioxidant gene of Saccharomyces cerevisiae. J. Biol. Chem. 268: 1681516821

Chae, H. Z., Robinson, K. Poole, L. B., Church, G., Storz, G. and Rhee, S. G. (1994) Cloning and sequencing of thiol-specific antioxidant from mammalian brain: alkyl hydroperoxide reductase and thiol-specific anti-oxidant define a large family of antioxidant enzymes. Proc. Natl. Acad. Sci.USA 91: 7017-7021

Chae, H. Z., Uhm, T. B. and Rhee, S. G. (1994) Dimerization of thiol-specific antioxidant and the essential role of cysteine 47. Proc. Natl. Acad. Sci.USA 91: 7022-7026

Chen, Q., Olashaw, N. and Wu, J. (1995) Participation of reactive oxygen species in the lysophosphatidic acid-stimulated mitogen-activated protein kinase kinase activation pathway. J. Biol. Chem. 270: 28499-28502

Chen, Z., Silva, H. and Klessing, D. F. (1993) Active oxygen species in the induction of plant systemic acquired resistance by salicylic acid. Science 262: 1883-1886

Choi, H.-J., Kang, S. W., Yang, C.-H., Rhee, S. G. and Ryu, S.-E. (1998) Crystal structure of a novel human peroxidase enzyme at $2.0 \mathrm{~A}$ resolution. Nature Struc. Biol. 5 : 400-406

Finkel, T. (1998) Oxygen radicals and signaling. Curr. Opinion Cell Biol. 10: 248-253

Freedman, R. B., Hirst, T. R. and Tuite, M. F. (1994) Protein disulphide isomerase: building bridges in protein folding. Trends. Biochem. Sci. 19: 331-336

Griendling, K. K., Minieri, C. A., Ollerenshaw, J. D. and Alexander, R. W. (1994) Angiotensin II stimulates NADH and NADPH oxidase activity in cultured vascular smooth muscle cells. Circ. Res. 74: 1141-1148

Hanks, S. and Quinn, M. (1991) Protein kinase catalytic domain sequence database: identification of conserved features of primary structure and classification of family members. Method Enzymol 200: 38-62

Hecht, D. and Zick, Y. (1992) elective inhibition of protein tyrosine phos-phatase activities by $\mathrm{H}_{2} \mathrm{O}_{2}$ and vanadate in vitro. Biochem. Biophys. Res. Commun. 188: 773-779

Hidalgo, E., Ding, H., and Demple, B. (1997) Redox signal transduction: mutations shifting [2Fe-2S] centers of the SoxR sensor-regulator to the oxidized form. Cell 88 121-129

Holmgren, A. (1989) Thioredoxin and glutaredoxin systems. J. Biol. Chem. 264: 1396313966

Huie, R. E. and Padmaja, S. (1993) The reaction of no with superoxide. Free Radical Res. Commun. 18: 195-199

Ischiropoulos, H. (1998) Living and dying with reactive species. Focus on "peroxynitrite induces apoptosis of HL-60 cells by activation of a caspase-3 family protease". Am. J. Physiol. 274: C8534

Jacobson, M. (1996) Reactive oxygen species and programmed cell death. Trends in Biochem. Sci. 21, 83-86

Jin, D.-Y., Chae, H. Z., Rhee, S. G. and Jeang, K.-T. (1997) Regulatory role for a nove human thioredoxin peroxidase in NF-kappaB activation. J. Biol. Chem. 272: 3095230961

Kang, S. W., Baines, I. C. and Rhee, S. G. (1998) Characterization of a mammalian peroxiredoxin that contains one conserved cysteine. J. Biol. Chem. 273: 6303-6311
Kang, S. W., Chae, H. Z., Seo, M. S., Kim, K., Baines, I. C. and Rhee, S. G. (1998) Mammalian peroxiredoxin isoforms can reduce hydrogen peroxide generated in response to growth factors and tumor necrosis factor-alpha J. Biol. Chem. 273: 62976302

Kim, K., Kim, I. H., Lee, L.-Y., Rhee, S. G. and Stadtman, E. R. (1988) The isolation and purification of a specific "protector" protein which inhibits enzyme inactivation by a thiol/Fe(III)/ $\mathrm{O}_{2}$ mixed-function oxidation system.J. Biol. Chem. 263: 4704-4711

Knebel, A., Rahmsdorf, H. J., Ullrich, A., and Herrlich, P. (1996) Dephos-phorylation of receptor tyrosine kinases as target of regulation by radiation, oxidants or alkylating agents. EMBO J. 15: 5314-5325

Konishi, H., Tanaka, M., Takemura, Y., Matsuzaki, H., Ono, Y., Kikkawa, U. and Nishizuka, $Y$. (1997) Activation of protein kinase $C$ by tyrosine phosphorylation in response to $\mathrm{H}_{2} \mathrm{O}_{2}$. Proc. Natl. Acad. Sci. USA 94: 11233-11237

Kourie, J. I. (1998) Interaction of reactive oxygen species with ion transport mechanisms Am. J. Physiol. 275: C1-24

Kretz-Remy, C., Mehlen, P., Mirault, M.-E. and Arrigo, A.-P. (1996) Inhi-bition of I kappa B-alpha phosphorylation and degradation and subsequent NF-kappa B activation by glutathione peroxidase overexpression.J. Cell. Biol. 133: 1083-1093

Krieger-Brauer, H. I. and Kather, H. (1995) Antagonistic effects of different members of the fibroblast and platelet-derived growth factor families on adipose conversion and NADPH-dependent $\mathrm{H}_{2} \mathrm{O}_{2}$ generation in 3T3 L1-cells. Biochem J. 307: 549-556

Lander, H. M., Milbank, A. J., Tauras, J. M., Hajjar, D. P., Hempstead, B. L., Schwartz, G. D., Kraemer, T. T., Mirza, U. A., Chait, B. T., Campbell-Burk, S. and Quilliam, L. A (1996) Redox regulation of cell signalling, Nature 381: 380-381

Lee, S.-R., Kwon K.-S., Kim, S.-R. and Rhee, S. G. (1998) Reversible inactivation of protein-tyrosine phosphatase 1B in A431 cells stimulated with epidermal growth factor. J. Biol. Chem. 273: 15366-15372

Lee, S. R., Kwon, K.-S., Kim, S.-R. and Rhee, S. G. (1998) Reversible inactivation of protein-tyrosine phosphatase $1 B$ in A431 cells stimulated with epidermal growth factor. J. Biol. Chem. 273: 15366-15372

Lee, Z. W. Kweon, S.-M., Kim, B.-C., Leem, S.-H., Shin, I., Kim, J.-H. and Ha, K.-S. (1998) Phosphatidic acid-induced elevation of intracellular $\mathrm{Ca}^{2+}$ is mediated by RhoA and $\mathrm{H}_{2} \mathrm{O}_{2}$ in Rat-2 fibroblasts. J. Biol. Chem. 273: 12710-12715

Levine, A., Tenhaken, R., Dixon, R. and Lamb C. (1994) $\mathrm{H}_{2} \mathrm{O}_{2}$ from the oxidative burs orchestrates the plant hypersensitive disease resistance response. Cell 79: 583-590

Levine, R. L., Mosoni, L., Berlett, B. S. and Stadtman, E. R. (1996) Methionine residues as endogenous antioxidants in proteins. Proc. Natl. Acad. Sci. USA 93: 15036-15040

Lo, Y. Y. C., Wong, J. M. S. and Cruz, T. F. (1996) Reactive oxygen species mediate cytokine activation of c-Jun $\mathrm{NH}_{2}$ - terminal kinases, J. Biol. Chem 271: 15703-15707

Lohse, D. L., Denu, J. M., Santoro, N. and Dixon, J. E. (1997) Roles of aspartic acid-181 and serine-222 in intermediate formation and hydrolysis of the mammalian proteintyrosine-phosphatase PTP1, Biochemsitry 36: 4568-4575

May, J. M. and De Haen, C. (1979) The insulin-like effect of hydrogen peroxide on pathways of lipid synthesis in rat adipocytes. J. Biol. Chem. 254: 9017-902

Meier, B., Radeke, H. H., Selle, S., Younes, M., Sies, H., Resch, K. and Habermehl, G. G. (1989) Human fibroblasts release reactive oxygen species in response to interleukin1 or tumour necrosis factor-alpha. Biochem J. 263: 539-545

Min, D. S., Kim, E. -G. and Exton, J. H.(1998) Involvement of tyrosine phosphorylation and protein kinase $C$ in the activation of phospholipase D by H2O2 in Swiss 3T3 fibroblasts. J. Biol. Chem. 273: 29986-29994

Moncada, S., Palmer, R. M. J. and Higgs, E. A. (1991) Nitric oxide: physiology, pathophysiology, and pharmacology. Pharmacol. Rev. 43: 109-142

Natarajan, V., Taher, M. M., Roehm, B., Parinadi, N. L., Schmid, H. H. O., Kiss, Z. and Garcia, J. G. N. (1993) Activation of endothelial cell phospholipase D by hydrogen peroxide and fatty acid hydroperoxide. J. Biol. Chem. 268: 930-937 
Ohba, M., Shibanum, M., Kuroki, K. and Nose, K. (1994) Production of hydrogen peroxide by transforming growth factor-beta 1 and its involve-ment in induction of egr-1 in mouse osteoblastic cells. J. Cell Biol. 126: 1079-1088

Pahl, H. C. and Baeuerle, P. A. (1994) Oxygen and the control of gene expression. BioEssays 16: 497-501

Robertson, F. M., Beavis, A. J., Oberyszyn, T. M., O'Conell, S. M., Dokidos, A., Laskin D.L., Laskin, J. D. and Reiners, J. J. Jr. (1990) Production of hydrogen peroxide by murine epidermal keratinocytes following treatment with the tumor promoter 12-0tetradecanoylphorbol-13-acetate. Cancer Res. 50: 6062-6067

Rosner, J. L. and Storz, G. (1997) Regulation of bacterial responses to oxidative stress. Curr. Top. Cell Regul. 35: 163-177

Runge M. et al., unpublished work

Schreck, R., Rieber, R. and Baeuerele, P. A. (1991) Reactive oxygen intermediates as apparently widely used messengers in the activation of the NF-kappa B transcription factor and HIV-1. EMBO J. 10: 2247-2258

Schreck, R., Rieber, P. and Baeuerle, P. A. (1991) Reactive oxygen intermediates as apparently widely used messengers in the activation of the NF-kappa $B$ transcription factor and HIV-1. EMBO J. 10: 2247-2258

Shirasu, K., Dixon, R. A. and Lamb, C. (1996) Signal transduction in plant immunity. Immunology 8: 3-7

Stadtman, E. R. and Oliver, C. N. (1991) Metal-catalyzed oxidation of proteins. Physiological consequences. J. Biol. Chem. 266: 2005-2008

Stadtman, E. R. and Berlett,B. S. (1998) Reactive oxygen-mediated protein oxidation in aging and disease. Drug Metabolism Reviews 30: 225-243

Sullivan, S. G., Chiu, D. T.-Y., Errasfa, M., Wang, J. M., Qi, J.-S. and Stern, A. (1994) Effects of $\mathrm{H} 2 \mathrm{O} 2$ on protein tyrosine phosphatase activity in HER14 cells. Free Radical Biol. Med. 16: 399-403

Sundaresan M., Yu, Z.-X., Ferrans, V., Irani, K. and Finkel, T. (1995) Requirement for generation of $\mathrm{H}_{2} \mathrm{O}_{2}$ for platelet-derived growth factor signal transduction. Science 270: 296-299

Sundaresan, M., Yu, Z. X., Ferrans, V. J., Sulciner, D. J., Gutkind, J. S., Irani, K., Goldschmidt-Clermont, P. J. and Finkel, T. (1996) Regulation of reactive-oxygenspecies generation in fibroblasts by Rac1. Biochem J. 318: 379-382

Suzuki, Y. J., Forman, H. J. and Sevanian, A.(1997) Oxidants as stimulators of signal transduction. Free Rad. Biol. and Med. 22, 269-285
Thannickal, V. J. and Fanburg, B. L. (1995) Activation of an $\mathrm{H}_{2} \mathrm{O}_{2}$-gener-ating NADH oxidase in human lung fibroblasts by transforming growth factor beta 1. J. Biol. Chem. 270: $30334-30338$

Thelen, M., Dewald, B. and Baggiolini, M. (1993) Neutrophil signal trans-duction and activation of the respiratory burst. Physiol. Rev. 73: 797-821

Ushio-Fukai, M., Zafari, A. M., Fukui, T., Ishizaka, N. and Griendling, K. K.. (1996) p22phox is a critical component of the superoxide-generating NADH/NADPH oxidase system and regulates angiotensin II-induced hypertrophy in vascular smooth muscle cells. J Biol. Chem. 271: 23317-23321

Yim, M. B., Chae, H. Z., Rhee, S. G., Chock, P. B. and Stadtman, E. R. (1994) On the protective mechanism of the thiol-specific antioxidant enzyme against the oxidative damage of biomacromolecules. J. Biol. Chem. 269: 1621-1626

Zhang, P., Liu, P., Kang, S. W., Seo, M. S., Rhee S. G. and Obeid, L. M.(1997) Thioredoxin peroxidase is a novel inhibitor of apoptosis with a mechanism distinct from that of Bcl-2. J. Biol. Chem. 272: 30615-30618

Zheng M., Slund F. and Storz G. (1998) Activation of the OxyR transcription factor by reversible disulfide bond formation. Science 279: 1718-1721

Zor, U., Ferber, E., Gergely, P., Szcs, K., Dormbradi, V. and Goldman, R. (1993) Reactive oxygen species mediate phorbol ester-regulated tyrosine phosphorylation and phospholipase A2 activation: potentiation by vanadate. Biochem. J. 295: 879-888 